\title{
PROCESS EFFICIENCY AND OUTCOME EFFECTIVENESS IN THE UNITED KINGDOM'S LOCAL AIR QUALITY MANAGEMENT REGIME
}

\author{
J.W.S. LONGHURST, A.O. OLOWOPOROKU, J. BARNES, T.J. CHATTERTON, E.T. HAYES \& J.G. IRWIN \\ Air Quality Management Resource Centre, University of the West of England, Bristol, United Kingdom
}

\begin{abstract}
The UK's Local Air Quality Management (LAQM) commences with a Review and Assessment which may lead to the declaration of an Air Quality Management Area (AQMA) where an exceedence of the Air Quality Objectives is confirmed. A declaration initiates the development of Air Quality Action Plan (AQAP) intended to provide solutions to the identified problems. There is no doubt that the LAQM framework has delivered a clear picture of elevated air pollution at specific locations in the UK, defined in temporal and spatial scales. However, the evidence to date suggests that delivering solutions to air quality problems is much more problematic, and has not been achieved at the rate expected when the framework was introduced in 1997. Despite the national policy intention and direction provided through the framework, the probability of achieving the traffic-related Air Quality Objectives by the set dates in the UK Regulations is uncertain. Using evidence from several studies undertaken by the authors, this paper considers the implication of distinct policy disconnects which are present in the LAQM process. The key conclusion implies transition from procedural compliance with the diagnostic process of LAQM towards a more holistic approach that will require new means of internal communication and co-operation and external consultation at the local and central government level and the ability to confront political and economic vested interest.

Keywords: Air Quality Management Area (AQMA), Air Quality Objectives, Environment Act, 1995, Local Air Quality Management (LAQM).
\end{abstract}

\section{INTRODUCTION}

Since the 1950s a series of policy interventions such as control of smoke and $\mathrm{SO}_{2}$ in urban areas, tighter regulation of industrial air pollution, and removal of lead in petrol, have been introduced to manage long-term and episodic air pollution in the UK. In more recent times, road transport sources account for a large proportion of the emissions of several air pollutants. The spatial importance of this on air pollution, due to the mobility of the vehicular sources, creates unique challenges to the traditional approach of managing air quality at point sources. At the European scale, vehicle manufacturing technology has been incentivised through the introduction of tighter EURO standards on vehicles and fuels to reduce vehicular emissions. Following the recommendations outlined in the Royal Commission on Environmental Pollution (RCEP) paper on Transport and the Environment in 1994, transport planners in the UK has explored alternative to road building through policy initiatives that extend the traditional link between congestion and traffic management to include the environment [1]. An example of such initiatives includes establishing of Low Emission Zones in urban areas where local air quality management control is enforced by allowing access only to green modes of transport such as cycles and electric vehicles.

However, the impacts of policy and technological interventions on emissions are often offset by the increase in local pollutant concentrations due to the scale of growth in car ownership, and associated increase in traffic levels [2]. Traffic growth in the UK increased by 88\% from 215 to 404 billion vehicle kilometres travelled between 1980 and 2007 [2]. This growth is attributed to the rise in personal income and the decline in the real cost of car against the rise in real costs of public transport fares [3]. The relationships between traffic and air pollution are complex, since measures that improve traffic flows often lead to latent traffic growth, longer distances and a net increase in concentrations 
and risk of public exposure to traffic-related air pollutants such as nitrogen oxides $\left(\mathrm{NO}_{2}\right)$ and particulates $\left(\mathrm{PM}_{10}\right)$ [4]. Increasing evidence which indicates an association between vehicular sourced pollutants and human mortality due to respiratory and cardiovascular diseases provided opportunities for campaigning groups to mobilise public opinion and the media to illustrate the scale and impact of air pollution due to traffic growth [5, 6]. Consequently, urban air pollution and public health was repositioned at the forefront of national and local political agenda in the late 1980s.

Based on the recommendations of the Expert Panel on Air Quality Standards (EPAQS), the UK government adopted a suite of numerical air quality objectives from the early 1990s, each with specified timescales. The objectives were determined by considering costs and benefits, and the feasibility and practicality of moving towards the EPAQS standards [7]. In 1995, the Local Air Quality Management (LAQM) framework was introduced through the Environment Act 1995 (Part IV, Air Quality) as an effect-based and risk management approach founded on a suite of Air Quality Objectives for ambient air pollutants. The framework sets out responsibilities for central and local government. In drawing up the Act, it was recognised that the previous point source control approach of domestic and industrial air pollution was no longer appropriate for the emerging episodes of multi-sourced, multipollutant, air pollution [8]. Local management was therefore placed at the heart of UK response to air pollution whilst maintaining, at a national level, a critical role in co-ordination and direction of local actions and the undertaking of such duties most effectively discharged at the level of the nation state.

Fundamental to the LAQM regime is the division of responsibility between central government and local government. Whilst LAQM is a local responsibility, central government has an overarching role in defining and framing the goals and policy underlining the framework, along with setting strategic directions and ensuring appropriate resourcing for national and local actions. There is no doubt that the LAQM framework has delivered a clear picture of elevated air pollution at specific locations in the UK, defined in the temporal and spatial scales. However, the evidence to date suggest delivering solutions to air quality problems is much more problematic, and has not been achieved at the rate expected when LAQM was introduced [8]. Despite the national policy intention and direction provide through the framework, the probability of achieving the traffic-related Air Quality Objectives by the set dates is uncertain. This paper, therefore, considers the implication of distinct policy disconnects which are present in the LAQM process. To identify these disconnects, the next section examines the LAQM framework in terms of its complexity and the solutions it has offered for tackling air pollution in the UK.

\section{LAQM AS A RISK-ASSESSMENT PROCESS WITH EFFECT-BASED OUTCOMES}

The Environment Act (Part IV Air Quality) 1995 set in motion the requirement for an Air Quality Strategy (AQS) by the UK Government. The AQS considered the historical legacy of air pollution, the contemporary nature of the air pollution challenge, and the adequacy of current controls, measures and priorities [9]. Through the AQS, the Government set out 'standards relating to the quality of air', and 'objectives for the restriction of the levels at which particular substances are present' in specific geographical locations outside buildings or other natural or man-made structures above or below ground where members of the public might be reasonably expected to be exposed over the relevant averaging period [10]. Standards are based on assessment of each pollutant on human health, while objectives are policy targets which are often expressed as a maximum ambient concentration which are not to be exceeded within a specified timescale [11]. The Environment Act 1995 and AQS both provide a framework in which national and local actions are required to identify and remediate areas of poor air quality through a series of duties and responsibilities on local authorities to review and assess local air quality against specific Air Quality Objectives [9]. Table 1 outlines important sections of the Act with regards to air quality management. 
Table 1: Part IV of UK Environment Act 1995 (Air Quality): Summary of Sections.

\begin{tabular}{|c|c|}
\hline Sections & Summary \\
\hline Section 80 & $\begin{array}{l}\text { Obliges the Secretary of State for Environment, Food and Rural Affairs (SoS) to } \\
\text { publish a National Air Quality Strategy as soon as possible. }\end{array}$ \\
\hline Section 82 & $\begin{array}{l}\text { Requires local authorities, unitary or district, to review air quality and to assess } \\
\text { whether the Air Quality Objectives are being achieved. Areas where objectives fall } \\
\text { short must be identified. }\end{array}$ \\
\hline Section 83 & $\begin{array}{l}\text { Requires a local authority, for any area where Air Quality Objectives are not being } \\
\text { met, to issue an order designating it an Air Quality Management Area (AQMA). }\end{array}$ \\
\hline Section 84 & $\begin{array}{l}\text { Imposes duties on a local authority with respect to AQMAs. The local authority } \\
\text { must carry out further assessments and draw up an air quality action plan (AQAP) } \\
\text { specifying the measures to be carried out and the time scale to bring air quality in } \\
\text { the area back within limits. }\end{array}$ \\
\hline Section 85 & $\begin{array}{l}\text { Gives reserve powers to cause assessments to be made in any area and to give } \\
\text { instructions to a local authority to take specified actions. Authorities have a duty to } \\
\text { comply with these instructions. }\end{array}$ \\
\hline Section 86 & $\begin{array}{l}\text { Imposes duties on the county council, where the district council is preparing an } \\
\text { AQAP, to submit proposals which outline the timescales for meeting the air quality } \\
\text { standards and objectives within the AQMA. }\end{array}$ \\
\hline Section 87 & $\begin{array}{l}\text { Provides the SoS with wide ranging powers to make regulations concerning air } \\
\text { quality. These include regulations on air quality objectives, the conferring of } \\
\text { powers and duties, the prohibition and restriction of certain activities or vehicles, } \\
\text { the obtaining of information, the levying of fines and penalties, the hearing of } \\
\text { appeals and other criteria. The regulations must be approved by affirmative } \\
\text { resolution of both Houses of Parliament. }\end{array}$ \\
\hline Section 88 & $\begin{array}{l}\text { Provides powers to the central government to make policy and technical guidance } \\
\text { which local authorities must have regard to in the implementation of the policy. }\end{array}$ \\
\hline
\end{tabular}

The AQS was founded upon the principles of sound science; health effects based regulation, costeffectiveness, proportionality, sustainability, precautionary approach and subsidiarity which to this day continue to inform its implementation. Key to the AQS has been the establishment of 'standards relating to the quality of air', and 'objectives for the restriction of the levels at which particular substances are present' in specific geographical locations outside buildings or other natural or manmade structures above or below ground where members of the public might be reasonably expected to be exposed over the relevant averaging period [10]. The 'standards' have been set as minimum of or zero risk level based on scientific and medical assessment of each pollutant. The 'objectives' set out policy targets expressed as a maximum ambient concentration and the extent to which the UK Government expect the standards are not to be exceeded within a specified timescale [11]. The Air Quality Objectives covers major pollutants with significant public health risks: lead, CO, 1,3-butadiene, $\mathrm{SO}_{2}, \mathrm{NO}_{2}$, benzene and $\mathrm{PM}_{10}$ (Table 2). The objectives were introduced as Regulations in 1997, revised in 2000 with further amendments in 2002 and 2007. In practice, most of the objectives laid down in regulations, apart from that of $\mathrm{NO}_{2}, \mathrm{PM}_{10}$ and $\mathrm{SO}_{2}$, have not been met. In Northern Ireland local authorities shadowed the process of LAQM until the Environment (Northern Ireland) Order, 2002 came into force which provided the Devolved Administration with equivalent responsibilities to their British counterparts, HM Government [12]. 
Table 2: Air Quality Objectives contained in the Air Quality (England) Regulations 2000 as amended (DEFRA, 2007).

\begin{tabular}{|c|c|c|c|}
\hline \multirow[b]{2}{*}{ Pollutant } & \multicolumn{2}{|c|}{ Air Quality Objective } & \multirow[b]{2}{*}{ Date to be achieved by } \\
\hline & Concentration & Measured as & \\
\hline \multirow[t]{2}{*}{ Benzene } & $16.25 \mu \mathrm{g} \mathrm{m}^{-3}$ & Running annual mean & 31.12 .2003 \\
\hline & $5 \mu \mathrm{g} \mathrm{m}^{-3}$ & Annual mean & 31.12 .2010 \\
\hline Carbon monoxide & $10.0 \mathrm{mg} \mathrm{m}^{-3}$ & $\begin{array}{l}\text { Maximum daily } \\
\text { Running 8-h mean }\end{array}$ & 31.12 .2003 \\
\hline 1,3 Butadiene & $2.25 \mu \mathrm{g} \mathrm{m}^{-3}$ & Running annual mean & 31.12 .2003 \\
\hline \multirow[t]{2}{*}{ Nitrogen dioxide } & $200 \mu \mathrm{g} \mathrm{m}^{-3}$ not to & $1 \mathrm{~h}$ mean & 31.12 .2005 \\
\hline & $\begin{array}{l}\text { be exceeded } \\
\text { more than } 18 \text { times } \\
\text { a year } \\
40 \mu \mathrm{g} \mathrm{m}^{-3}\end{array}$ & Annual mean & 31.12 .2005 \\
\hline \multirow[t]{2}{*}{ Lead } & $0.5 \mu \mathrm{g} \mathrm{m}^{-3}$ & Annual mean & 31.12 .2004 \\
\hline & $0.25 \mu \mathrm{g} \mathrm{m}^{-3}$ & Annual mean & 31.12 .2008 \\
\hline \multirow{2}{*}{$\begin{array}{l}\text { Particles }\left(\mathrm{PM}_{10}\right) \\
\text { (gravimetric) }\end{array}$} & $50 \mu \mathrm{g} \mathrm{m}^{-3}$ not to be & $24 \mathrm{~h}$ mean & 31.12 .2004 \\
\hline & $\begin{array}{l}\text { exceeded more than } \\
35 \text { times a year } \\
40 \mathrm{~g} \mathrm{~m}^{-3}\end{array}$ & Annual mean & 31.12 .2004 \\
\hline \multirow[t]{7}{*}{ Sulphur dioxide } & $350 \mu \mathrm{g} \mathrm{m}^{-3}$ not to be & $1 \mathrm{~h}$ mean & 31.12 .2004 \\
\hline & exceeded more than & $24 \mathrm{~h}$ mean & 31.12 .2004 \\
\hline & 24 times a year & 15 min mean & 31.12 .2005 \\
\hline & $\begin{array}{l}125 \mu \mathrm{g} \mathrm{m}^{-3} \text { not to be } \\
\text { exceeded more than } \\
3 \text { times a year }\end{array}$ & & \\
\hline & $266 \mu \mathrm{g} \mathrm{m}^{-3}$ not to be & & \\
\hline & exceeded more than & & \\
\hline & 35 times a year & & \\
\hline
\end{tabular}

While the AQS is regarded as statements of policy intentions and options, the legal frameworks for achieving the standards and objectives were provided by the Air Quality Regulations HM Government [13]. The objectives specified in Regulations represent the Government's judgement of achievable air quality by specified timescales on the evidence of costs and benefits and technical feasibility. The objectives apply in areas where the public may be exposed for the averaging time of the relevant objective such as building facades, public open spaces, pavements and gardens; local authorities undertaking assessments of air quality are under a duty to identify if relevant public exposure exists in any area where exceedence of an air quality objective is identified [8]. Where relevant exposure and exceedence of the objectives exist, local authorities are then required to declare such designated areas as Air Quality Management Areas (AQMAs). The original dates set in the Air Quality Regulations for the achievement of the Air Quality Objectives has now passed adding urgency to the implementation of AQAP measures. 
As shown in Fig. 1, Sections 82-84 of the Environment Act 1995 imposes duties on local authority (districts, unitary and metropolitan councils) to undertake a review of local air quality 'for the time being, and the likely future quality within the relevant period, of air within the authority's area', and assess whether the air quality standards and objectives are being achieved; or are likely to be achieved within the relevant period stated in the Regulations [10]. Where the Air Quality Objectives are not likely to be achieved, local authorities are required to designate AQMAs and develop an AQAP within 18 months. The AQAP specifies measures proposed by the local authorities to work 'in pursuit' of the Air Quality Objectives where national actions on their own will not be able to deliver improvement [14]. There is local flexibility in the extent of the spatially designated zones that can be designated as AQMA as long as there is evidence of risk of relevant public exposure in relation to the averaging time of the Air Quality Objectives in those areas. An AQMA represents the conclusion of a technical assessment of air quality carried out in accordance with central government guidance against the air quality objectives. In declaring an AQMA a local authority will have satisfied itself, relevant stakeholders and central government that a risk of exceeding one or more objectives, by the date the objective is to be achieved, has been demonstrated in an area in which public exposure for a relevant period is or will be present.

In carrying out these functions, the local authority is required to consult with various stakeholders, including local authorities with which it shares a border and any relevant county council or highway authority affected by the review or AQAP. This implies an inherent multi-disciplinary, integrated and collaborative approach towards the management of local air pollution. Internal and external working groups between environmental health officers (EHOs) who are the lead local authority functions for LAQM and officers from other sectors, such as transport, land-use and economic planners have been shown to be important elements in the efficiency of the LAQM process [15].

The LAQM framework therefore comprises two distinct phases. First is the diagnostic phase which involves undertaking Review and Assessment in order to identify areas of existing and potential areas

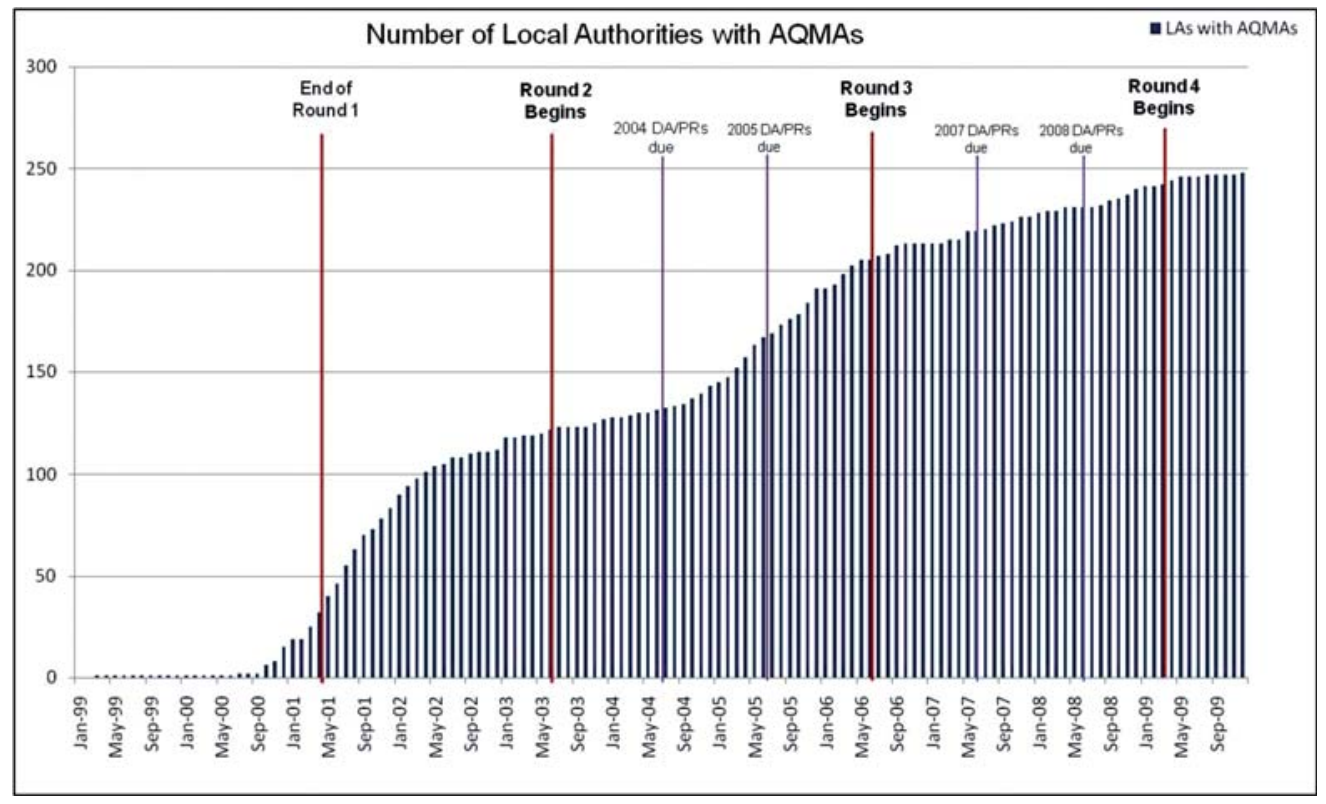

Figure 1: Number of UK local authorities with Air Quality Management Areas. 
within their administrative jurisdiction where the objectives may be exceeded. The second phase is that of solutions identified in the AQAP which outlines the mitigation and management measures towards achieving the Air Quality Objectives. The LAQM framework requires a stepped approach of increasing complexity to assess both current levels of air pollution and the likelihood of future compliance with the Air Quality Objectives [14]. The Review and Assessment is a cyclical process which may, or may not, lead to the declaration of an AQMA and the subsequent development of an AQAP. The Review and Assessment process is taken in distinct temporal phases of work known as 'rounds', during which the Government exercises its power as a statutory consultee to appraise the work of local authorities and acts to assure itself that the statutory duties of the local authorities are being undertaken in an appropriate manner.

The first round of the Review and Assessment process, which began in 1998, resulted in 129 local authorities declaring one or more AQMAs. A second round of Review and Assessment began in 2003, and a third round commenced in 2006. In the interval between each round, local authorities are required to issue an annual Progress Report, the purpose of which is to report new monitoring data, describe any new developments that might affect air quality and to maintain the momentum of air quality management in the local authority.

At the beginning of the LAQM process in 1998, very few local authorities except those located in large urban or metropolitan areas were expected to declare AQMAs. As shown in Fig. 1, the number of local authorities that had declared AQMAs had risen to 248 in December 2009 representing 56\% of the total number of district and unitary authorities in the UK. These AQMAs have principally been declared for $\mathrm{NO}_{2}$, with a significant number of $\mathrm{PM}_{10}$ and a smaller number of $\mathrm{SO}_{2}$ declarations. A full list of local authorities with AQMAs may be seen at http://aqma.defra.gov.uk/list.php.

While the Review and Assessment phase is effective at diagnosing air quality problems, the AQAP phase cannot yet be judged to be a successful policy intervention. Large proportions of the identified exceedences are due to emissions from road transport sources (Table 3). This trend implies that local authorities without transport planning responsibilities, in the case of two-tier local government

Table 3: Percentage ${ }^{a}$ of AQMAs declared by source.

\begin{tabular}{lcccccc}
\hline & & & & \multicolumn{3}{c}{ Northern } \\
& England & London & Scotland & Wales & Ireland & Total \\
\hline Total number of LA & 292 & 33 & 32 & 22 & 26 & 405 \\
Number of LA with AQMA & 172 & 33 & 12 & 8 & 11 & 236 \\
Domestic & $1 \%$ & $0 \%$ & $8 \%$ & $0 \%$ & $64 \%$ & $4 \%$ \\
Transport/Industry & $5 \%$ & $12 \%$ & $8 \%$ & $0 \%$ & $0 \%$ & $5 \%$ \\
Transport/Domestic & $<1 \%$ & $0 \%$ & $0 \%$ & $0 \%$ & $0 \%$ & $<1 \%$ \\
Transport/Industry/Domestic & $1 \%$ & $0 \%$ & $0 \%$ & $0 \%$ & $0 \%$ & $<1 \%$ \\
Unknown & $2 \%$ & $0 \%$ & $0 \%$ & $0 \%$ & $0 \%$ & $2 \%$ \\
Local roads & $83 \%$ & $85 \%$ & $92 \%$ & $75 \%$ & $64 \%$ & $82 \%$ \\
Highways/Motorways & $14 \%$ & $0 \%$ & $0 \%$ & $13 \%$ & $0 \%$ & $10 \%$ \\
Mixed roads & $19 \%$ & $9 \%$ & $8 \%$ & $13 \%$ & $0 \%$ & $16 \%$ \\
Industrial & $7 \%$ & $0 \%$ & $8 \%$ & $13 \%$ & $0 \%$ & $6 \%$ \\
\hline
\end{tabular}

aPercentage of the total number of local authorities that have declared an AQMA in that region. LA: Local authority; AQMA: Air Quality Management Area

Source: Review and Assessment Database. 
arrangement, have limited powers to initiate direct actions amid concerns about the political impact of measures that will affect the car-driving public. As a result, the LAQM framework has been unable to get real traction on meeting the identified challenge of air pollution in the UK.

\section{EXPLORING AND DEFINING THE POLICY DISCONNECTS IN THE LAQM PROCESS AND OUTCOMES}

Arguably, the UK LAQM process is a strong example of public health oriented, risk management environmental policy leading to targeted, proportionate and cost-effective actions focussed on a specific area. Effect-based management of locally specified air pollution 'hotspots' through the LAQM process is similar in concept to the idea introduced in the Clean Air Act, 1956 of a smokeless zone; although in practice the AQMAs are more complex entities as they can relate to a wider range of pollutants. The Environment Act 1995 places a duty on Government to support local authorities through the provision of guidance and other initiatives. This has included the development of high quality national monitoring networks, the creation of high resolution emission inventories, the provision of training for local authority personnel, the development of Technical and Policy Guidance documents to assist local authorities in their LAQM duties, and the provision of additional financial assistance to help authorities purchase monitoring equipment and other technical resources. An important support element has been the development of web, telephone and email help desks to assist air quality officers in carrying out their duties [7]. The periodic review of the Air Quality Regulations to reflect developments in European legislation, technological and scientific advances, improved air pollution modelling techniques and an increasingly better understanding of specific pollutants and their impact on human health is an important part of the process. This regular review provides dynamism and statutory weight to the development of air quality policy in the UK based on sound and growing scientific evidence [8].

The LAQM framework incorporates scientific developments in tackling local air pollution within a rigorous and continuous assessment reflecting changes in both scientific and socio-economic understanding of air pollution. This has led to the identification of air quality problems in areas that were previously overlooked. In this context, the accumulating AQMAs declared in each successive round of the review and assessment process provides an indication of the success and effectiveness of LAQM as a policy tool for diagnosing air quality problems [16, 17]. The lack of revocations of traffic-related AQMA however demonstrates the failure of the AQAP process to reduce these problems. This is supported by a recent study by Longhurst et al. [8] which indicates that the LAQM process itself has delivered little or no improvement through the measures that were identified in the AQAP, especially with regard to traffic-related pollution [8].

The complexity of the contemporary air quality challenge offers some explanations for this failure. The development of AQAPs has proceeded at a much slower rate than the diagnostic Review and Assessment work. Even where an AQAP is being implemented there is limited evidence to show that such plan has led to the reduction in high concentrations of named pollutants through the measures implemented. This reveals an obvious limitation in the LAQM framework in terms of policy disconnect between the diagnosis of the problem and the solutions proffered.

There are complex and shifting mixes of challenges faced by the local authorities in implementing an AQAP. These include political, economic, institutional, and communication barriers, which are highlighted by limited capacity and capability of the local government. Implementing measures that are identified in the AQAP are often beyond the remit of the departments and, in some cases, the local authorities responsible for undertaking the LAQM framework. In practice, the outcome of the LAQM framework indicates that the solution to air quality is not the remediation of a technical problem alone. 
It is this ongoing concern and necessity to provide traction to the LAQM framework that underlies the integration of air quality management into Local Transport Plan (LTP) process in 2006. The Local Government White Paper, Strong Local Leadership - Quality Public Services outlined opportunities for English local authorities with AQMAs associated with emissions from transport sources the opportunity to incorporate their AQAPS into their LTP process [18]. The LTP is principally a bidding document for resources from central government to support transport intentions. It sets out plans and policies in relation to a suite of priorities identified by the central government. The LTP appears to offer advantages with respect to implementing air quality improvement plans where transport is the cause of the air quality problem. Integration of AQAPs into the LTP process therefore offers the prospect of a more holistic approach to the remediation of poor air quality and the possibility of securing funding under the LTP settlement grant to support measures proposed in the AQAPs.

However, the LTP is a separate government requirement, managed by the Department for Transport, with different reporting timescale to that of LAQM. As illustrated in Fig. 2, there are institutional complexities at the local government level where the transport planning department is situated in a higher tier of local government than the district authority with administrative responsibilities for air quality management. Thus the apparent advantage of incorporating the AQAP within the LTP is itself fraught with new and often intractable difficulties. Studies by Olowoporoku et al. [19, 20], showed that air quality was given low priority within the LTP in comparison to the other 'traditional' transport policy concerns such as congestion, accessibility and road safety [19, 20]. The studies also highlight unequal expectations from the EHOs and transport planners as a barrier to 'effective

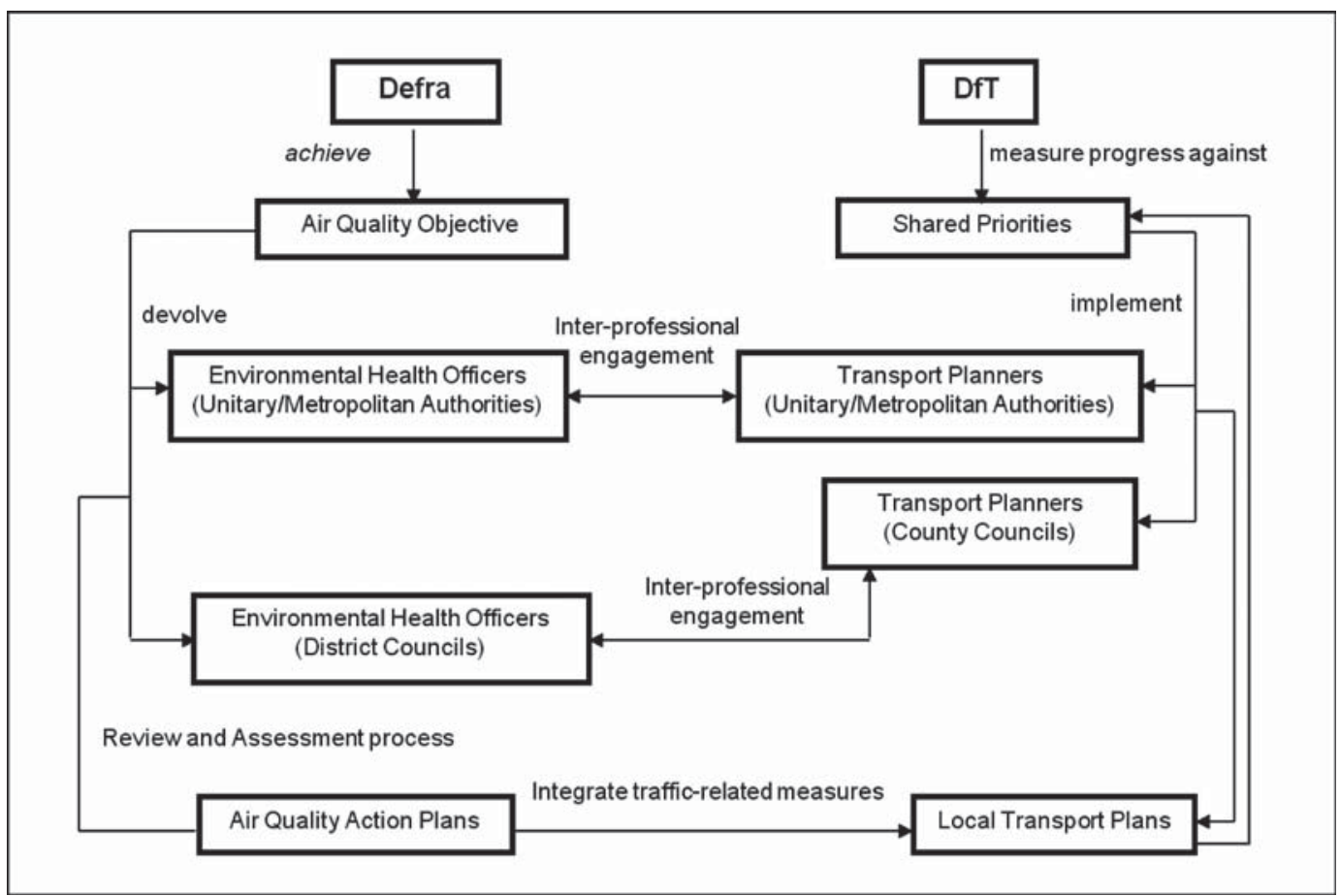

Figure 2: Institutional complexities involved in integrating air quality action plans into local transport planning process in English local authorities. 
communication' necessary for policy integration, especially in a multi-tier local government structure. While it is safe to assume that the LTP2 framework will contribute to the improvement of air quality management at the local level, there are concerns about the limitations of the LTP2 process in producing significant improvements in local air quality [20].

These concerns are due to two major factors. Firstly, the impact of LTP interventions on local air quality management is reduced by the institutional complexities and legislative frames in which both policies operates limitations. Evidence shows that while the majority of the EHOs and transport planners surveyed think that LTP2 is an appropriate framework for improving local traffic-related air quality, very few hold the opinion that the integration will lead to reduction in the number of AQMAs by the end of the LTP2 cycle in 2011 [20]. The result indicates that operational efficiency in managing traffic-related air quality will not necessarily translate into the delivery of better air quality. For example, there are no incentives or consequences to encourage the local authorities to achieve the Air Quality Objectives during the LTP2 cycle. While the EU Limit values for $\mathrm{NO}_{2}$ and $\mathrm{PM}_{10}$ are legally binding parameters that must not be exceeded by the UK government, the Air Quality Objectives in the AQS are 'statement[s] of policy intentions or policy targets' without any legal requirements on the local authorities to meet them [7]. Consequently, this creates limited opportunity for local authorities to implement decisive traffic measures aimed at reducing emissions as part of the AQAP process.

Secondly, and contributory to the first factor, is that air quality management is often supplanted by economic and other broader transport policy interests within the LTP2 process. Appraisal of 20 LTP2 documents by Olowoporoku et al. [20] showed that the design and implementation of major transport schemes is often done without adequate material consideration for their immediate and long-term impact on air pollution [20]. According to a transport planner who participated in the study, some of the measures identified in the LTP2 document are not intended to be delivered by the LTA: 'Although we include their AQAPs into the LTP, which shows that we signed up to it, but doesn't necessarily mean we will deliver it.' Some other transport planners admitted that the LTAs often preferred 'soft' measures which enable the persuasive power of the local authorities to facilitate the use of public or alternative transport modes; rather than implementing 'hard' engineering measures that have better chance of improving local traffic-related air quality. In a resource constrained environment, it is not surprising for the LTAs to adopt a pragmatic approach to prioritise time and resource only when and where it is needed most.

\section{RECONNECTING THE POLICIES AND PRIORITIES}

The air quality policy framework in the UK has undergone a radical transformation since 1995, having exchanged a source control approach for a complex but integrated, risk management effectsbased LAQM regime. However, there are inherent deficiencies in the regime in relation to the AQAP phase where it can be argued that political and economic risks are more significant than in the diagnostic phase of Review and Assessment process. The inability of local authorities to implement effective AQAP might be due to a poorly constructed and imprecisely calibrated plan in relation to the scale of the identified problem. This argument may be valid in a few instances but the quality assurance elements of the LAQM regime which requires all plans to be approved by the central government for technical compliance and likely efficacy suggests that this is not a sufficient explanation.

From inception it was clear that the success of LAQM would require connection between policies, adequate resourcing, clear communication of priorities and a shared ownership of responsibility for achieving outcomes between central and local government [21]. Now, after 13 years of LAQM the extent of the disconnects between central and local governments in substantive areas of policy implementation is evident and urgently requires corrective action. There are three immediate recommendations that are required in order to address this. 
Firstly, the interconnection between LAQM and other policy packages needs to be made explicit both nationally and locally. Since air quality policy is closely linked with a number of other policy areas such as health, transport, land-use planning and climate change, significant steps towards policy integration is therefore needed. For example, there are opportunities for developing integrated climate change and air quality policy at regional and local government level due to the commonality of sources between $\mathrm{NO}_{2}, \mathrm{PM}_{10}$ and $\mathrm{CO}_{2}$. Although health and climate change impacts are already considered within major transport schemes, the approach to this should be more intentional and proactive. Integrative approaches to the assessment of transport planning frameworks should be adopted to include more radical approach (such as Low Emission Zones) which re-focuses the economic and public health impact of managing traffic-related air pollution.

Secondly, vested interests and resourcing of the LAQM regime needs to be re-examined. There are potential benefits to policy and practice if the two central government departments responsible for air quality management and transport planning - Defra and DfT - work together in aligning the traffic-related Air Quality Objectives as targets that have to be achieved within the LTP lifecycle. As highlighted in this paper, the primary limitation of LAQM is the policy disconnect between the diagnosis of the local air quality issue and the solutions offered within it. While the LTP2 framework has provided better opportunities through which the major specific problem, trafficrelated air pollution, can be properly addressed, environmental and health impact data are yet to fully influence the transport planning decision-making process at the local level. Since air quality problems are not economically, physically or politically tangible compared with other LTP2 shared priorities, transport planners often see its management as a discrete policy which is separate from other issues within the transport planning policy agenda. Addressing this will involve redefining the associated linkage between traffic growth, congestion, climate change, air quality, and public health. Traffic-related Air Quality Objectives should be re-focused within transport policy in order to ensure shared responsibilities for achieving them between the transport planners the Environmental Health Officers. This will reduce the institutional complexities as a result of the separation between the identifying and the correcting party as both are required to meet the same targets and objectives. To facilitate this, joint guidance documents and support mechanisms can be provided by central government to the local authorities in order to clarify their expectations of local authority actions. This is not a recommendation for integrating the administrative functions of Defra and DfT, nor that of the Transport planners and the Environmental Health Officers. Rather, it is an opportunity to synchronise targets and resources between two interconnected policy spheres.

Thirdly, communicating the rationale for LAQM and the necessity for action must be framed in acceptable ways for broad public consumption. While there are wide held concerns over the health impact of traffic-related air quality, it is difficult to translate this importance in reality to the public or elected members when compared for example to that of traffic congestion and road safety [20]. Although political support for action does not necessarily respond to increased public awareness about an issue, reviewing the mechanisms through which the public and the local government elected members are engaged on the health, economic and social impacts of air pollution will provide added benefits for air quality management. This idea is based on the concept of 'informed citizenry', described by Peter et al. [22] as a product of community-based engagement programmes in which the public are treated as active participants rather than as consumers or customers [22]. Several other studies have shown that tapping into the cohesion and motivational drives within existing social networks and community groups has improved the delivery of environmental policies in the past, contributing, for example, to the achievements of community-based energy conservation projects $[23,24]$. 


\section{CONCLUSION}

The current UK approach to the management of air quality, particularly at the local level, is one of a public health orientated environmental management programme, setting out a risk-based framework, leading to targeted, proportionate and cost-effective actions focussed on a single area of the environment. There are clear health-based standards, indicating 'acceptable' and 'unacceptable' levels of exposure risks to air pollution. In the 13 years of LAQM since the first air quality strategy was published in 1997 there has been a significant enhancement in the ability of decision makers to take account of air quality in routine decision making. The quality of information available to decision makers has improved as the LAQM process has developed appropriate methods for local, repetitive, comprehensive, and quality assured Review and Assessment procedures [8]. These Reviews and Assessments are able to draw upon high quality emissions and monitoring data via a number of specially commissioned web resources and support structures guiding the LAQM process. Therefore, the national Air Quality Strategy appears to meet the aims set for it in terms of policy intentions and the clarity of the procedures to diagnose the air quality problem. However, the situation with the AQAP elements of the LAQM process is not as clear. The urgency of the policy intent is not present to the same extent as the Review and Assessment component of the framework, despite initial dates for meeting the Air Quality Objectives having passed.

The measures within an AQAP are designed to explicitly target the sources contributing to an exceedence of an Air Quality Objectives. In practice, this means that traffic sources are the target of the measures and this brings a range of technical, economic and political costs and risks for a local authority. Identifying and managing these risks is now critically important if air quality improvements are to be achieved. Local and central governments need to identify new ways of explaining air quality risks and impacts in order to build alliances to deliver improvements. This implies transition from procedural compliance with the diagnostic process of LAQM towards achievement of improved air quality outcomes. This will require new means of internal communication and co-operation and external consultation and the ability to confront political and economic vested interest. It is probable that the metrics used in explaining air quality are too technical for the majority of the population and it has been suggested that the current information campaigns through which the public and the local government elected members are engaged on the health, economic and social impacts of air pollution are not efficient to support real political and societal change [25].

Whilst some of the processes and procedures need refinement and enhancement to become effective in providing solutions, the position in terms of diagnosis provides encouragement that the challenge posed by poor air quality can be identified. The flexible, responsive system, which has created a strong flow of information between national and local governments, in both directions, is at the heart of the difference between contemporary air quality management and traditional strategies of pollution control. The challenge now is to extend the effective strategies delivering good air quality diagnosis into the AQAP phase so that information about the scale and complexity of local air quality problems is translated into effective delivery strategies for the timely improvement of air quality problems. A critical issue for the further development of air quality management policy and practice will be to ensure appropriate integration with other policies such as transport, health, land-use and climate change. Whether or not political and economic vested interests can exert undue influence remains to be seen, but if the public health benefits of improved air quality are to be realised then these challenges must be confronted and overcome. 


\section{REFERENCES}

[1] RCEP, Transport and the Environment. Eighteenth Report of the Royal Commission on Environmental Pollution. The Stationery Office: London, Cm 2674, 1994.

[2] Department for Transport, Transport Trends: 2008 edition. The Stationery Office: London, 2009.

[3] Chatterton, T., Coulter, A., Musselwhite, C., Lyons, G. \& Clegg, S., Understanding how transport choices are affected by environment and health: views expressed in a study on the use of carbon calculators. Public health, 123(1), pp. 45-49, 2009. doi:http://dx.doi.org/10.1016/j. puhe.2008.10.022 doi:http://dx.doi.org/10.1016/j.puhe.2008.10.022

[4] Banister, D., The sustainable mobility paradigm. Transport Policy, 15(2), pp. 73-80, 2008. doi:http://dx.doi.org/10.1016/j.tranpol.2007.10.005

[5] Paulley, N., Recent studies on key issues in road pricing. Transport Policy, 9(3), pp. 175-177, 2002. doi:http://dx.doi.org/10.1016/S0967-070X(02)00026-4

[6] Pope, C., Burnett, R.T., Thun, M.J., Calle, E.E., Krewski, D., Ito, K. \& Thurston, G.D., Lung cancer, cardiopulmonary mortality, and long-term exposure to fine particulate air pollution. Journal of American Medical Association, 287, pp. 1132-1141, 2002. doi:http://dx.doi. org/10.1001/jama.287.9.1132

[7] Longhurst, J.W.S., Beattie, C.I., Chatterton, T.J., Hayes, E.T., Leksmono, N.S. \& Woodfield, N.K., Local air quality management as a risk management process: assessing, managing and remediating the risk of exceeding an air quality objective in Great Britain. Environment International, 32, pp. 934-947, 2006. doi:http://dx.doi.org/10.1016/j.envint.2006.06.006

[8] Longhurst, J.W.S., Irwin, J.G., Chatterton, T.J., Hayes, E.T., Leksmono, N.S. \& Symons, J.K., The development of effects based air quality management regime. Atmospheric Environment, 43(1), pp. 64-78, 2009. doi:http://dx.doi.org/10.1016/j.atmosenv.2008.09.050

[9] Beattie, C.I., Longhurst, J.W.S. \& Woodfield, N.K., Air quality management: evolution of policy and practice in the UK as exemplified by the experience of English local government. Atmospheric Environment, 35, pp. 1479-1490, 2001.

[10] HM Government, Environment Act 1995. The Stationary Office: London, 1995.

[11] Department for Environment, Food and Rural Affairs, The Air Quality Strategy for England, Scotland, Wales and Northern Ireland, Vol. 1. Defra: London, 2007.

[12] HM Government, The Environment (Northern Ireland) Order 2002. The Stationary Office: London, 2002.

[13] HM Government, Air Quality Regulations 1997. The Stationary Office: London, 1997.

[14] Department for Environment, Food and Rural Affairs and National Assembly for Wales, Part IV of the Environment Act 1995 Local Air Quality Management. Policy Guidance LAQM. PG (03). The Stationery Office: London, 2003.

[15] Beattie, C.I., Longhurst, J.W.S. \& Elsom, D.M., Evidence of integration of air quality management in the decision making processes and procedures of English local government. Local Environment, 9, pp. 255-270, 2004. doi:http://dx.doi.org/10.1080/1354983042000219360

[16] Department for Environment, Food and Rural Affairs, The Air Quality Strategy for England, Scotland, Wales and Northern Ireland, Vol. 1. The Stationery Office: London, 2007.

[17] Ing, C., Beattie, C. \& Longhurst, J.W.S., Progress with implementing local air-quality management in rural areas of England. Journal of Environmental Management, 61(2), pp. 137-147, 2001. doi:http://dx.doi.org/10.1006/jema.2000.0391

[18] HM Government, Strong Local Leadership - Quality Public Services White Paper. The Stationery Office: London, 2001. 
[19] Olowoporoku, A.O., Hayes, E.T., Leksmono, N.S., Longhurst, J.W.S. \& Parkhurst, G., Are environmental health officers and transport planners in English local authorities working together to achieve air quality objectives? Air Pollution XVI, eds C.A. Brebbia \& J.W.S. Longhurst, WIT Press: Southampton and Boston, pp. 607-615, 2008. doi:http://dx.doi. org/10.1080/09640561003613179

[20] Olowoporoku, A.O., Hayes, E.T., Leksmono, N.S., Longhurst, J.W.S. \& Parkhurst, G.A., Longitudinal study of the links between local Air Quality Management and Local Transport Planning policy processes in England. Journal of Environmental Planning and Management, 53(3), pp. 385-403, 2010. doi; http://dx.doi.org/10.1016/1352-2310(96)00114-8

[21] Longhurst, J.W.S., Lindley, S.J., Watson, A.F.R. \& Conlan, D.E. The introduction of local air quality management in the United Kingdom. A review and theoretical framework. Atmospheric Environment, 30, pp. 3975-3985, 1996.

[22] Peter, M., Fudge, S. \& Sinclair, P. Mobilising community action towards a low-carbon future: opportunities and challenges for local government in the UK. Energy Policy, 30(12), pp. 7596-7603, 2010. doi:http://dx.doi.org/10.1016/j.enpol.2010.01.044

[23] Halpern, D., Aldridge, S. \& Fitzpatrick, S., Social Capital: A Discussion Paper. Performance and Innovation Unit: London, 2002.

[24] Walker G.P. \& Cass, N. Carbon reduction, 'the public' and renewable energy: engaging with socio-technical configurations, Area, 39(4), pp. 458-469, 2007. doi:http://dx.doi.org/10.1111/ j.1475-4762.2007.00772.x

[25] Faulkner, M. \& Russell, P. Review of Local Air Quality Management. A report to Defra and the devolved administrations. Stationery Office: London, 2010. 